\title{
Wagner's Classification for Management and Evaluation of Diabetic Foot: A Prospective Study
}

\author{
Prashant G.K. ${ }^{1}$, Suryanarayan Reddy $\mathbf{V}^{2}$ \\ ${ }^{1}$ Assistant Professor, ${ }^{2}$ Professor, \\ Department of General Surgery, Chalmeda Anand Rao Institute of Medical Sciences, Karimnagar. \\ Corresponding Author: Suryanarayan Reddy V
}

\section{ABSTRACT}

Background: In our community diabetes is one of the most common co-morbid illnesses. Out of its several complications in long course diabetic foot is one of them. Morbidity and mortality due to this complication is a major health issue.

Objective: This study is undertaken for management and evaluation of foot ulceration to avoid amputation of lower extremities due to diabetic foot disease.

Methods: This prospective observational study conducted between July 2019 and September 2020, 40 patients with diabetic foot admitted to Department of General Surgery, Chalmeda Anand Rao Institute of Medical Sciences, Karimnagar (TS) were subjected to surgical treatment depending upon the Wagner's classification. Data was collected and analyzed by statistical software SPSS V 25.

Results: Majority of the patients presented with higher grade and with poor glycemic control at the time of presentation. Conservative management with antibiotics was useful in a small subset of the patients. Majority of the patients needed surgical treatment in the form of debridement to amputations.

Conclusion: Patient education and strict glycemic control can reduce the burden of diabetic foot. Early diagnosis and hospitalization, appropriate treatment including medical and surgical treatment according to the grade can reduce the morbidity mortality and improve the outcome of the disease.

Keywords: Antibiotics; Amputation; Wagner classification; Complications; Glycemic control

\section{INTRODUCTION}

Sugar plays very important role in functioning of our body, this sugar in the blood is main source of energy which gets form the food we eat, but when this sugar increases in the body or in the blood and too high, it is called as high blood sugar or Diabetes. Now a days this disease is very commonly found in the population. Diabetes is one of the chronic diseases; this disease occurs either when the body can't use the insulin produces or when the pancreas does not produce sufficient insulin. Insulin is the hormone which regulates blood sugar in the body, when pancreas does not produce sufficient hormone in the body then sugar in blood get increases and condition of high blood sugar occurs, it is also called hyperglycemia, which is common effect of high blood sugar.

According to the International Diabetes Federation (IDF) in 2020, 463 million people have diabetes in the world and out of this 88 million people belong to the Southeast Asia region. Out of the 88 million from Southeast Asia 77 million people belongs to only India. In $20208.7 \%$ of teens aged bellow 19 years having diabetes which is more (4.4\%) than age group young adults 20-29 years. 36.9\% of seniors aged $>60$ Years having diabetes in this current year.

There are four categories of diabetes are recognized. Insulin-dependent diabetes mellitus (IDDM) called as Type 1 Diabetes, in which body does not produce sufficient insulin and immune system destroys cells in 

study.

pancreas which produce insulin. When produced insulin not used properly by our body called Type 2 Diabetes, which can develop at any age, mostly in middle age and older people. Some woman during the pregnancy develops diabetes called as gestational diabetes, which goes away after baby born. Inherited form of diabetes is monogenic diabetes which is less common. People with diabetic can develop health problem like heart disease, stroke, kidney disease, eye problem, foot problem, nerve damage etc. Out of all the diabetic health problems approximately $10 \%-25 \%$ diabetics will develop some foot complications, during the course of illness from simple calluses to major abscesses and osteomyelitis. Lower extremity complication and leg amputation is 40 times higher in diabetic patients compare to the nondiabetic and this diabetic foot ulcers are main cause of hospitalization in diabetic.

To avoid amputation of lower extremities and early recognition and proper treatment of diabetic foot lesion primarily management of diabetic foot should be focused. ${ }^{[1]}$ For grading ulceration and management of foot complication many several classifications exist. ${ }^{[2]}$ Simplest and best known for evaluation and management of diabetic foot ulceration well established and widely used is Wagner's wound classification, which give descriptions of ulcers to varying degrees and provide a guide to planning treatment strategies. $^{[3]}$ This classification system asses presence of gangrene or osteomyelitis. System consisting of six ulcer grades, ranging from 0 to 5 developed in the 1970 s. Thus, present prospective observational study undertaken for management and evaluation of diabetic foot ulceration to avoid amputation of lower extremities of tertiary care hospital, Karimnagar.

\section{MATERIALS AND METHODS}

This Prospective observational study was conducted in the Department of General Surgery, Chalmeda Anand Rao Institute of Medical sciences, Karimnagar. Total 40 patients were included in the study between July 2019 to March 2020. Patients with Chronic Diabetic Foot and previous amputations were also included in the study. Data were collected by detailed history, clinical examination, wound or ulcer and were recorded in the pre-designed proforma. Age, sex, socioeconomic status, duration and type of diabetes, Wagner's classification, examination findings, blood investigations, renal function test, swab of the wound. X-ray and treatment provided were collected.

Table 1 : Wagner's classification for diabetic foot disease (adopted from Levin and O'neals)

\begin{tabular}{|l|l|}
\hline Grade & Description \\
\hline Grade 0 & High risk foot and no ulceration \\
\hline
\end{tabular}

\begin{tabular}{ll} 
Grade 0 & High risk foot and no ulceration \\
\hline & Superficial Ulcer; Total destruction of the thickness
\end{tabular} Grade 1 of the skin

Grade 2 Deep Ulcer (cellulitis); Penetrates through skin, fat, Grade 2 ligaments not affecting bone

Grade 3 Osteomyelitis with Ulceration or abscess

Grade 4 Gangrenous patches limited to toes or part of the foot

Grade 5 Gangrene of the entire foot

Statistical Analysis: Collected data was entered in Microsoft excel 2016, for further analysis. Qualitative data was presented by percentage and association between the variable shown by using chi-square/fisher exact test. Test of Significance was 5\% level of Significance. Data was analyzed by using SPSS version 25.

\section{RESULT}

Table 2: Distribution of Socio - Demographic Variable

\begin{tabular}{|l|l|l|}
\hline Parameters & Frequency & Percent \\
\hline Age & 4 & 10 \\
\hline$<40$ Years & 20 & 50 \\
\hline $41-50$ Years & 12 & 30 \\
\hline $51-60$ Years & 4 & 10 \\
\hline$>60$ Years & 31 & 77.5 \\
\hline Sex & 9 & 22.5 \\
\hline Male & 1 & 2.5 \\
\hline Female & 1 & 97.5 \\
\hline Type of Diabetes & 39 & 15 \\
\hline Type 1 & 6 & 60 \\
\hline Type 2 & 24 & 25 \\
\hline Socio Economic Status & 10 & 40 \\
\hline Lower Class & 16 & 60 \\
\hline Middle Class & 24 \\
\hline Upper Class & \\
\hline Site of Lesion & \\
\hline Toe & \multicolumn{1}{|l|}{} \\
\hline Foot &
\end{tabular}

Present study conducted with 40 samples in the Department of General Surgery, CAIMS Karimnagar, from the data 
Prashant G.K. et.al. Wagner's classification for management and evaluation of diabetic foot: a prospective study.

analysis we found the results discussed below. Table 1 shows the sociodemographic table of the patients.

From the above socio-Demographic table it is observed that $77.5 \%$ of the male was affected by diabetic foot ulceration compared to female $(22.5 \%)$. Nearly $80 \%$ of the patients aged group of 41-50 years and 51-60 years affected by diabetic foot, having $97.5 \%$ of type 2 diabetic. $85 \%$ of the patients were from middle class and upper class. $60 \%$ of foot ulceration observed on foot than Toe shown in above Table 1.

Distribution of some clinical findings shown in Table 2 revealed that, preoperatively we sent swab taken from wound for culture thus causative organism found that, $50 \%$ of the patients affected by Staphylococcus aureus bacteria in their wound and $27.5 \%$ were affected by mixed culture. Thus, according to the Wagner's classification $33.5 \%$ of the patient were having grade 3 ulceration followed by Grade2 (22.5\%), Grade 4 (20\%), Grade 1 $(15 \%)$.

Table 3: Distribution of Clinical findings
\begin{tabular}{|l|l|l|}
\hline Parameters & Frequency & Percent \\
\hline Culture & 20 & 50 \\
\hline Staphylococcus aureus & 11 & 27.5 \\
\hline Mixed & 9 & 22.5 \\
\hline None & 3 & 7.5 \\
\hline Wagner's Classification & 6 & 15 \\
\hline Grade 0 & 9 & 22.5 \\
\hline Grade 1 & 13 & 32.5 \\
\hline Grade 2 & 8 & 20 \\
\hline Grade 3 & 1 & 2.5 \\
\hline Grade 4 & 20 & 50 \\
\hline Grade 5 & 11 & 27.5 \\
\hline Treatment & 6 & 15 \\
\hline Amputation & 2 & 5 \\
\hline Debridement & 1 & 2.5 \\
\hline Antibiotic Alone & \\
\hline I and D of abscess & 34 & 85 \\
\hline Skin Graft for chronic ulcer & 6 & 15 \\
\hline Follow Up For 4 Months & \\
\hline Healed & Not Healed & \\
\hline
\end{tabular}

About treatment of these foot ulceration for $50 \%$ of the patients needed some form of amputation which were in serious condition, followed by $27.5 \%$ of the patients needed Debridement, $15 \%$ of them required debridement. Follow up after 4 months observed that out of 40 patients $34(85 \%)$ healed after treatment.

Table 4: Association of some parameter with follow up to 4 Months

\begin{tabular}{|c|c|c|c|c|c|}
\hline \multirow{2}{*}{\multicolumn{2}{|c|}{ Parameters }} & \multicolumn{2}{|c|}{ Follow Up 4 Months } & \multirow[t]{4}{*}{ Fisher Exact test } & \multirow[t]{2}{*}{ P-value } \\
\hline & & Healed & Not Healed & & \\
\hline \multirow[t]{2}{*}{ Gender } & Male & $26(65)$ & $5(12.50)$ & & \multirow[t]{2}{*}{1.0} \\
\hline & Female & $8(20)$ & $1(2.50)$ & & \\
\hline \multirow[t]{6}{*}{ Wanger's Classification } & Grade 0 & $3(7.50)$ & $0(0)$ & \multirow[t]{6}{*}{8.623} & \multirow[t]{6}{*}{$0.053(\mathrm{NS})$} \\
\hline & Grade 1 & $6(15)$ & $0(0)$ & & \\
\hline & Grade 2 & $9(22.50)$ & $0(0)$ & & \\
\hline & Grade 3 & $11(27.50)$ & $2(5)$ & & \\
\hline & Grade 4 & $5(12.50)$ & $3(7.50)$ & & \\
\hline & Grade 5 & $0(0)$ & $1(2.50)$ & & \\
\hline \multirow[t]{5}{*}{ Treatment } & Amputation & $15(37.50)$ & $5(12.50)$ & \multirow[t]{5}{*}{2.925} & \multirow[t]{5}{*}{$0.602(\mathrm{NS})$} \\
\hline & Debridement & $10(25)$ & $1(2.50)$ & & \\
\hline & Antibiotic Alone & $6(15)$ & $0(0)$ & & \\
\hline & I and D of abscess & $2(5)$ & $0(0)$ & & \\
\hline & Skin Graft for chronic ulcer & $1(2.50)$ & $0(0)$ & & \\
\hline \multirow[t]{4}{*}{ Age } & $<40$ Years & $3(7.50)$ & $1(2.50)$ & \multirow[t]{4}{*}{9.19} & \multirow[t]{4}{*}{$0.009 * *(\mathrm{HS})$} \\
\hline & $41-50$ Years & $19(47.50)$ & $1(2.50)$ & & \\
\hline & 51-60 Years & $11(27.50)$ & $1(2.50)$ & & \\
\hline & $>60$ Years & $1(2.50)$ & $3(7.50)$ & & \\
\hline
\end{tabular}

\section{DISCUSSION}

Diabetes is associated with complications in its long run. Foot infection and subsequent amputation of a lower extremity are one of the most common reasons for hospitalization. As observed in our study, it is more common in males. More common age group was between 4060 in our study. The hallmark of diabetic foot is its gross infection and major contributing factors for late presentation are poor knowledge about the disease, undetected diabetes, trust in faith healers, bare foot gait. Peripheral neuropathy and infection are common risk factors diabetic foot. In our study mixed infection, includes aerobes, anaerobes were common.

Gender: In the present study proportion of male was comparatively more than female 

study.

in the ratio of $3.44: 1$, similar result was observed in the study conducted by Ali SM et $a^{[4]}$ as there were $65 \%$ males and $35 \%$ females.

Age: In this study $90 \%$ of the patients were lying in the age group of 41-60 and >60 Years, this proportion of age group was greater than result obtained in the study conducted by Ahmad Wet al ${ }^{[5]}$.

Site of Lesion: Maximum foot ulcer found at foot $24(60 \%)$ compared to toe $16(40 \%)$, these results are similar to study conducted by Apelquist study conducted in 1988 where foot is common site for ulceration ${ }^{[6]}$.

Treatment Modalities: In the present study amputation for diabetic foot was $50 \%$, in study conducted by "Rooh-ul-mukim" observed that amputation was observed in $48 \%$ of the patients ${ }^{[7]}$, and Chellan $\mathrm{G}$ et al ${ }^{[8]}$ found that major amputations comprised about $29.1 \%$ and minor amputation $70.9 \%$ among the diabetic patients with foot infection also it was suggested that infection was the significant cause for the amputation in approximately $90 \%$ of study population.

Microbiological Culture: Collected wound swab sent for microbial culture, from which we found that from $50 \%$ of patients Staphylococcus aureus was isolated and from other $50 \%$ of the patients mixed organism was isolated. In one study conducted, $35 \%$ of the patients encountered with polymicrobial infection ${ }^{[7]}$, and this polymicrobial Infection is a major factor in the pathogenesis of diabetic foot and associated with ischemia leads to amputation.

Wagner's Classification: In the present study $32.5 \%$ patients had grade 3, $22.50 \%$ had grade 2 , and $20 \%$ had grade 4 and $15 \%$ had grade 1 foot ulceration was observed in diabetic foot according to the Wagner's classification. In the Study conducted by "Rooh-ul-muqim" majority of the cases was in Grade 2 and $3^{[7]}$.
Follow Up after 4 Months: In our study out of all $85 \%$ of the patients were healed within 4 months those who were admitted in the hospital, no mortality was observed in our study. In Rooh-ul-muqim et al. study out of 100 patients 96 discharged and 4 expired ${ }^{[7]}$.

\section{CONCLUSION}

We all knows that prevention is always better than cure, from all above results and analysis it is confirmed that early presentation of the cases and hospitalization of the patients leads to confirmed healing of the foot ulcers and avoid mortality and amputation of lower extremities. Wagner's classification with better outcome helps to confirm appropriate treatment to proper grade of lesion. Also, this study suggests that education about hygiene of legs and effective glycemic control plays the key role to avoid such foot ulceration.

\section{Limitation of Study:}

1. Study is in bound of limitation of sample size, present study had very less sample size to estimate prevalence of diabetic foot ulcer, also for management of the cases.

2. Other parameter like other comorbidities, eating habits, addiction like smoking, alcoholics not included in the study.

\section{Acknowledgement: None}

\section{Conflict of Interest: None}

\section{Source of Funding: None}

Ethical Approval: Approved by Institutional ethical committee.

\section{REFERENCES}

1. American Diabetes Association. Diabetes Facts and Figures, 2000, American Diabetes Association, Alexandria, VA, 2000.

2. Wagner FW: The dysvascular foot: a system of diagnosis and treatment. Foot Ankle 2:64 -122, 1981. 
Prashant G.K. et.al. Wagner's classification for management and evaluation of diabetic foot: a prospective study.

3. Connor H Some Historical Aspects of Diabetic Foot Disease. Diabetes Metab Res Rev. 2008; 24(1):S7-S13.

4. Ali SM1, Basit A, Sheikh T, Mumtaz S, Hydrie MZ. Diabetic foot ulcer--a prospective study. J Pak Med Assoc 2001 ;51(2):78-81.

5. Ahmad W, Khan IA, Ghaffar S, Al-Swailmi FK, Khan I.Risk factors for diabetic foot ulcer. J Ayub Med Coll Abbottabad 2013; 25(1-2):16-8.

6. Carter DM, Lin AN. Wound Healing And Epidermolysis Bullosa. Arch Dermatol. 1988; 124(5):732-3.

7. Rooh-Ul-Muqim, Ahmed M, Griffin S. Evaluation and Management of Diabetic
Foot According To Wagner's Classification. A Study of 100 Cases. J Ayub Med Coll Abbottabad. 2003; 15(3):39-42.

8. Chellan G, Srikumar S, Varma AK, Mangalanandan TS, Sundaram KR, Jayakumar RV et al. Foot Care Practice The Key To Prevent Diabetic Foot Ulcers In India. Foot (Edinb). 2012; 22(4):298-302.

How to cite this article: Prashant G.K., Suryanarayan Reddy V. Wagner's classification for management and evaluation of diabetic foot: a prospective study. International Journal of Research and Review. 2021; 8(7): 327-331. DOI: https://doi.org/10.52403/ijrr.20210745 